\title{
ANÁLISE E COMPARAÇÃO DA DENSIDADE DA MACROFAUNA ENTRE ÁREAS DE PASTAGEM E CAFEICULTURA
}

\author{
André Alves Pinheiro' \\ Daniel Soares Ferreira ${ }^{2}$ \\ Ícaro Klippel Lugão ${ }^{3}$ \\ Wilian Rodrigues Ribeiro ${ }^{4}$ \\ Romero Cancela Rocha Júnior ${ }^{5}$ \\ Wesley Catein dos Santos ${ }^{6}$ \\ Melissa Alvarenga de Oliveira ${ }^{7}$ \\ Manoel Victor Borges Pedrosa ${ }^{8}$
}

Resumo: As funções exercidas pela macrofauna no solo são de grande importância para os atributos do solo, tanto químicos, como físico, a qual tem como responsabilidade a circulação de água e ar, a fertilidade e a manutenção da estrutura do solo. No presente trabalho, o objetivo é quantificar e identificar os indivíduos no solo e relacionar o resultado com a cultura e com o manejo edáfico utilizado. Para isto realizou-se coletas em campo, separando as amostras das duas distintas áreas, objetivando posterior análise em laboratório para quantificar os animais e separá-los por ordem taxonômica. Na área de pastagem encontrou-se mais organismos em relação a área de cafeicultura, como por exemplo, organismos da ordem Arachnida e Coleoptera estavam presentes somente em solo sob pastagem. Constatou-se que há menor presença de indivíduos no solo em áreas com manejo constante. Com esta pesquisa, podemos propor a alteração em alguns métodos utilizados na propriedade, buscando a melhoria da produtividade.

Palavras-chave: Fauna edáfica; Biodiversidade do solo; Manejo do solo.

\footnotetext{
1 Graduando em Agronomia da Universidade Federal do Espirito Santo - UFES, Brasil. E-mail: aalvespinheiro7@gmail.com.

2 Graduando em Agronomia da Universidade Federal do Espirito Santo - UFES, Brasil. E-mail: danielufes@live.com.

3 Graduando em Agronomia da Universidade Federal do Espírito Santo - UFES, Brasil. E-mail: icarokl@hotmail.com.

4 Graduando em Agronomia da Universidade Federal do Espírito Santo - UFES, Brasil. E-mail: wilianrodrigues@msn.com.

5 Graduando em Agronomia da Universidade Federal de Viçosa - UFV, Brasil. E-mail: romerocancella@hotmail.com.

6 Graduando em Agronomia da Universidade Federal do Espírito Santo - UFES, Brasil. E-mail: wesleycateins@outlook.com.

7 Graduanda da Universidade Federal do Espírito Santo - UFES, Brasil. E-mail: melissalvarengao@gmail.com.

8 Biólogo, Mestrando em Produção Vegetal pela Universidade Federal do Espírito Santo - UFES, Brasil. E-mail: mvborgespedrosa@gmail.com.
} 